\title{
De la Problemática del Modernismo: La Crítica y el "Cosmopolitismo"
}

$\mathrm{D}$ ESDE la primera crítica importante de la obra epónima inicial del modernismo - -la de Azul, suscrita por don Juan Valera en 1888hasta las más recientes apreciaciones de Darío - la de Enrique Anderson Imbert en la tercera edición de su Historia de la literaiura bispanoame. ricana, 1961, por ejemplo-, el "cosmopolitismo" ha venido siendo señalado como una de las características modernistas.* Decía Valera: "Si el libro, impreso en Valparaíso, en este año de 1888, no estuviese en muy buen castellano, lo mismo pudiera ser de un autor francés, que de un italiano, que de un turco ơ un griego. El libro está impregnado de espíritu cosmopolita. Hasta el nombre y apellido del autor, verdaderos o contrahechos y fingidos, hacen que el cosmopolitismo resalte más. Rubén es judaico, y persa es Darío: de suerte que, por los nombres, no parece sino que Ud. quiere ser o es de todos los pueblos, castas y tribus."1 $Y$ dice Anderson Imbert: "En Rubén Darío el sentimiento aristocrático, desdeñoso para la realidad de su tiempo, se objetiva en una poesía exótica, cosmopolita, reminiscente de arte y nostálgica de épocas históricas."2 En los años que median entre 1888 y 1961 muchos otros críticos han calificado de cosmopolita la obra de Darío y la de los modernistas en

* Trabajo leído en el grupo Spanish 6: Spanish-American Literature, Colonial and Nineteenth Century, en la 76a. reunión anual de la Modern Language Association of America, en Chicago, Illinois, el 27 de diciembre de 1961.

1 Juan Valera, Cartas americanas, Primera serie (Madrid, 1889), pp. 215216. (Las subsiguientes citas de esta obra en el texto llevan allí, entre paréntesis, indicación de la p. o pp. de que proceden). Como es sabido, las dos cartas sobre Azul que Valera dirigió a Darío, reproducidas en el indicado libro, aparecieron primeto en "Los Lunes" del diario madrileño El Imparcial, el 22 y el 29 de octubre de 1888 , respectivamente.

2 Enrique Anderson Imbert, Historia de la literatura bispanoamericana, $3^{\text {a }}$ ed. (México 1961), I, 368. 
general. ${ }^{3}$ La frecuentación de esas obras de crítica nos revela, sin embargo, que tal calificación adquiere un contenido y un valor muy diferentes en los distintos críticos. Vientos de encontradas doctrinas se arremolinan sobre ese punto. Por ello mismo, un breve recorrido por algunas de las opiniones representativas en tal materia pudiera ilustrannos acerca de las fluctuaciones en la valoración del modernismo y acerca de los distintos puntos de enfoque críticos; pudiera ser una pequeña nota para la historia de la crítica.

Por si se arguyera que ésta ha inventado la abstracción del cosmopolitismo dariano y modernista, recuérdese que el propio Darío utilizó ese término al referirse a "la revolución moderna o modernista" en las letras hispánicas. Dijo, por ejemplo, en una ocasión: "tuvimos que ser políglotas y cosmopolitas y nos comenzó a venir un rayo de luz de todos los pueblos del mundo"; y en otras habló de sus "vistas cosmopolitas" - del "soplo cosmopolita" que animó al modernismo." A confesión de parte, relevación de prueba; pero volvamos a los críticos.

Aunque lectores apresurados así lo hayan afirmado, el cosmopolitismo de Darío no fue considerado vitando por don Juan Valera. Este era un hombre demasiado enterado para no reconocer, como él mismo puntualizó el propio año 1888, que en el siglo xIX "ha habido y hay renacimiento universal cosmopolita" (p. 3). Y aunque lo hispánico le importaba mucho, como un buen individualista y como un escritor en-

3 La certificación por la crítica del espíritu cosmopolita que anima la obra de Darío y de los modernistas en general puede documentarse con innúmeras citas: "Un hálito de la Cosmópolis moderna le trae efluvios de la vida mundial," $o$, suya es una plenitud de "erudición cosmopolita y de experiencia humana", (Pedro Henríquez Ureña, "Rubén Darío," en Ensayos criticos [La Habana, 1905], cit. por su Obra critica [México, 1960], pp. 105 y 96). "El espíritu cosmopolita que caracteriza nuestra renovación literaria" (Arturo Marasso Rocca, Estudios literarios [Buenos Aires, 1920], p. 96). "En América había prevalecido, dentro del movimiento modernista, la influencia francesa, y, en general, se había manifestado un interés literario de carácter cosmopolita" (Max Henríquez Ureña, El retorno de los galeones [Madrid, 1930], p. 76). El modernismo resulta de "a new cosmopolitan concept of culture and life in the community of Spanish American nations" y está lleno de "aristocratic cosmopolitan leanings" (John A. Crow y John E. Englekirk, respectivamente, en E. Herman Hespelt et al., An Outline History of Spanish American Literature [New York, 1941], pp. 79 y 119). "In its sources the movement was cosmopolitan and afrancesado" (Arturo Torres-Rioseco, The Epic of Latin American Literature [New York, 1942], p. 90). Etc., etc.

4 Cit. por Allen W. Phillips, "Rubén Darío y sus juicios sobre el modernismo," Revista Iberoamericana, XXIV (1959), 53, 58. 
tusiasmado con el arte de Darío, no pudo menos de decirle en tono de elogio, "si no tiene. Ud. carácter nacional, posee carácter individual" (p. 218); pero como pensaba también que el espíritu cosmopolita habia penetrado en el nicaragüense "no diré exclusivamente - escribe-, pero sí principalmente a través de libros franceses" (p. 251), acabó recomendándole una ampliación de su ámbito cultural: "yo aplaudiría muchísimo más, si con esa ilustración francesa que en usted hay se combinase la inglesa, la alemana, la italiana, y ¿por qué no la española también?" (p. 236). Si esto no es incitar al Darío veinteañero de 1888 hacia el cosmopolitismo cultural, hacia ese decimonónico renacimiento cosmopolita antes mencionado, no sé lo que será. 5

En análoga línea de pensamiento cosmopolizante de fines del siglo pasado hallamos a Baldomero Sanín Cano quien en un ensayo ya antiguo, titulado "De lo exótico," luego recogido en varios de sus libros colectáneos, decía: "Las gentes nuevas del Nuevo Mundo tienen derecho a toda la vida del pensamiento. No hay falta de patriotismo ni apostasía de raza en tratar de comprender lo ruso, verbigracia, y de asimilarse uno lo escandinavo. Lo que resulta, no precisamente reprensible, sino lastimoso con plenitud, es llegar a Francia y no pasar de ahí. El colmo de estas desdichas es que talentos como el de Rubén Darío, y capacidades artísticas como la suya, se contenten, de lo francés, con el verbalismo inaudito de Víctor Hugo o con el formalismo precioso, con las verduras inocentes de Catulle Mendès. Francia sola da para más," y "Ensanchémoslos [nuestros gustos] en el tiempo y en el espacio; no nos

5 En una carta a Marcelino Menéndez y Pelayo, fechada en Madrid el 18 de septiembre de 1892, reiteraba Valera que "el extracto, la refinada tintura... de todo lo novísimo de extranjis" que había en Darío producía "mucho de insólito, de nuevo, de inaudito, de raro, que agrada y no choca porque está hecho con acierto y buen gusto" y que lo "asimilado e incorporado de todo lo reciente de Francia y de otras naciones, está mejor entendido que aquí [en España] se entiende, más hondamente sentido, más diestramente reflejado y mejor y más radicalmente fundido con el ser propio y castizo de este singular semi-español, semi-indio" (Epistolario de Valera y Menéndez y Pelayo, 1877-1905, eds. Miguel Artigas Ferrando y Pedro Sáinz Rodríguez [Madrid, 1946], pp. 446-447). No se me oculta, sin embargo, que posteriormente Valera, en su reseña de Prosas profanas, pedía a Darío que prescindiera un poco de las modas de París y que poetizata asuntos "más propios de su tierra y de su casta" y "objetos más ideales"; pero también es cierto que el motivo de esta crítica se encuentra en lo que Valera consideraba la "monotonía" de la temática del "amor sexual y puramente material" que le parecía prevalecer en el libro, aunque sin por ello desconocer "Ia novedad y belleza" de sus versos ni a Darío como el poeta "más original y característico que ha habido en América hasta el día presente" (Juan Valera, Ecos argentinos [Madrid, 1901], p. 186. Esta reseña apareció ptimero en El Correo Español, de Buenos Aires, de 20 de junio de 1897). 
limitemos a una raza, aunque sea la nuestra, ni a una época histórica, ni a una tradición literaria."6

Tanto Valera (1824-1905) como Sanín Cano (1861-1957) representan en este punto una actitud crítica para la cual, en uno y otro lado del Atlántico, la cultura era la cultura europea. Su ecuación mental es: Cosmopolitismo $=$ Cultura occidental. A1 decir del colombiano, esta cultura en "su difusión en todo el orbe conocido establece diferencias de grado pero no esenciales."7 Valera quisiera ver el cosmopolitismo de Dario más ampliamente europeo, menos principalmente atado a la interpretación francesa. Sanín Cano, cuyo sentir en este punto, según se ha visto, coincide bastante con el de Valera, es, sin embargo, más auténticamente cosmopolita aún que él, está menos atado a raíces de raza y de tradición. Sanín estaba más próximo que Valera al cosmopolitismo que, por definición, carece de prejuicios y lazos locales o nacionales. Hijos ambos y sus ideas de una era en que la unidad de la cultura occidental parecía rehacerse por vez primera - aunque sobre otras basesdesde su tompimiento en los siglos de la Reforma y la Contra-Reforma, constatan el uno y el otro el saber cosmopolita de Darío y quisieran hallar en su obra más bien más que menos cosmopolitismo. Su actitud hacia éste es intrínsecamente positiva, con algunas diferencias de grado - digámoslo parafraseando al propio Sanín- que no de esencia.

En una actitud respecto al cosmopolitismo de Darío que roza con la que acabamos de reseñar puede verse a José Enrique Rodó (1872-1917). Muchas veces se ha repetido lo que él, en un ensayo famoso sobre Prosas profanas, afirmó: "Indudablemente, Rubén Darío no es el poeta de América"; 8 pero se olvida que en el propio ensayo Rodó indicaba igualmente su creencia de que fuera de las fuentes de inspiración constituidas por la Naturaleza y por la vida de los campos, "Ios poetas que quieran expresar, en forma universalmente inteligible para las almas superiores, modos de pensar y de sentir cultos y bumanos, deben renunciar a un verdadero sello de americanismo original" (p. 258), es decir, que deben ser cultural y expresivamente cosmopolitas. Rodó, hastiado indudablemente del americanismo literario de los románticos, los costumbristas, los gauchescos, de un americanismo limitado a aspectos geográficos y "pintorescos," pre-

6 Baldomero Sanin Cano, Tipos, Obras, Ideas (Buenos Aires, 1949), pp. 168 y 169.

7 Ibid, p. 170.

8 José Enrique Rodó, Cinco ensayos (Madrid, s.f.), p. 257. Las subsiguientes citas de esta obra en el texto llevan allí, entre paréntesis, indicación de la p. o pp. de que proceden. 
fiere ver subsumirse lo americano en lo culto y lo bumano - son sus palabras. Por ello no le asombra la ausencia en Darío de "todo sentimiento de solidaridad social y todo interés por lo que pasa en torno suyo" (p. 261), observando que si en lo extensivo esto limita al poeta, le impide ser popular, le hace en cambio poeta de selección (p. 266), lo que en sus términos de referencia es señal de superioridad. Así observa su "cosmopolitismo ideal" (p. 274). Rodó deplorará la obra "frívola y vana" de los imitadores de Darío, pero no dejará de señalar que la de éste es, en cambio, intensa y seria, "es en el arte una de las formas personales de nuestro anárquico idealismo contemporáneo" (p. 309). El anárquico idealismo, el cosmopolitismo ideal de Darío, de sus contemporáneos de fin de siglo, el suyo propio - "Yo soy un moder" nista también" (p. 308) - le parecían por entonces a Rodó maneras de superar el americanismo rústico y costumbrista de románticos y gauchescos, la vulgaridad del realismo y del naturalismo literarios y la sequedad del positivismo filosófico. Rodó veía en el Darío de Prosas profands un artista plenamente civilizado, sin ninguna parte primitiva ( $\mathrm{p}$. 301), es decir, un hermano en la labor de hacer de América otra Europa, de la cultura americana una cultura parigual de la europea, en los términos en que otro modernista, Amado Nervo, sucintamente lo expuso: "Nosotros no queremos estar pintorescos: queremos ser los continuadores de la cultura europea (y si es posible los intensificadores)." 9

Si contrastamos las anteriores opiniones española e hispanoamericanas con la del norteamericano Alfred L. Coester (1874-1958), encontraremos que también para él, en 1916, el cosmopolitismo de los modernistas hallaba su explicación en que: "In rebellion against the narrowing influence of regionalism, they hoped to find a common basis for their literary art in the theory that their civilization was European."10 Vale decir, que como Valera o Rodó, Coester interpretaba el cosmopolitismo modernista como europeísmo, y todo como una rebelión contra el regionalismo tan evidente en las doctrinas de nacionalismo literario del pasado entonces reciente. Si se arguyera contra tal europeísmo que Darío y los demás modernistas eran muy aficionados no sólo a lo europeo sino a mucho de lo que habitualmente entendemos por "exotismo," o sea, lo no perteneciente a nuestra más inmediata civilización, la occidental (aunque ello sea contrario al sentido etimológico de todo lo de afuera,

9 Amado Nervo, Obras completas, II (Madrid, 1952), 399.

10 Alfred Coester, The Literary History of Spanish America (New York, 1916), p. 451. 
externo, extranjero, que derechamente es el de la palabra "exótico"), pudiera contestarse con Pedro Henríquez Ureña (1884-1946) que eso era también en los modernistas de origen europeo, hijo (por si se hubiera olvidado el exotismo romántico) del exotismo parnasiano que apuntaba "a todos los países y a todos los tiempos como campos en que cosechar." 11

Pronto, sin embargo, comienza a notarse en algunos críticos hispanoamericanos cierta desazón frente al cosmopolitismo modernista. Rufino Blanco-Fombona (1874-1944), por ejemplo, exclamaba: "Carecemos de raza espiritual. No somos hombres de tal o cual país; somos hombres de libros; espíritus sin geografía, poetas sin patria, autores sin estirpe, inteligencias sin órbita, mentes descastadas. A nuestro cerebro no llega, regándolo, la sangre de nuestro corazón, o nuestro corazón no tiene sangre, sino tinta, la tinta de los libros que conocemos."' 2 Nótese el cambio de tono que se percibe en el texto de Blanco-Fombona al compararlo con el de sus antecesores en la crítica del modernismo. En Valera, en Sanín Cano, en Rodó, hay un reconocimiento del cosmopolitismo como deseable elemento de cultura superior. El tono de Blanco-Fombona, en cambio, indica su irritación con él y presagia su abanderamiento en el "criollismo" literatio. Su explicación del cosmopolitismo modernista se basa en presuposiciones de carácter socio-cultural: Ese cosmopolitismo es un reflejo del "momento de incertidumbre mental y racial de América" y los escritores modernistas son unos desarraigados - recuérdese el tan aducido "Yo detesto la vida y el tiempo en que me tocó nacer," del Darío de Prosas profanas-por ser precisamente "de su época y de su tierra." 13 Esos escritores buscaban su mundo en los libros, no en la realidad en torno, porque ésta era una realidad en parte primitiva y en parte positivista, materialista, negociante, que repugnaba a su idealismo. El mundo europeo y cosmopolita a que se evadían y que adoraban (y que no era ciertamente el mundo de los comerciantes de Bergen o de los industriales de Lyon o de Milán), era el mundo de los libros europeos que leían; los libros de sus hermanos en idealismo, desde Ibsen a Verlaine y D'Annunzio. Cosmopolitismo era, pues, para Blanco-Fombona, desarraigamiento, descastamiento, cultura libresca, una estación de tránsito en un momento de incertidumbre americana; y por eso pidió, en un texto fechado en 1911, una reacción contra él, una afirmación de crio-

11 Pedro Henríquez Ureña, Las corrientes literarias en la América bispánica (México, 1949), p. 175.

12 Rufino Blanco-Fombona, El modernismo y los poetas modernistas (Madrid, 1929), p. 29.

13 Ibid., p. 25. 
llismo, al objeto de que siendo menos de Europa fueran los americanos más universales. ${ }^{14}$

Simplificando bastante, en obsequio de la brevedad, puede decirse que las dos líneas socio-culturales de interpretación del cosmopolitismo modernista que en Blanco-Fombona se perciben, han sido ampliamente desarrolladas por la crítica. Juan Marinello (n. 1899), por ejemplo, en 1937, veía en el modernismo el resultado del instante en que América quería igualarse a Europa y superarla (Recuérdese la frase de Amado Nervo antes citada). ¿Cómo hacerlo? Por la imitación y la posesión de las excelencias culturales de las metrópolis europeas. Consecuencia de ello fue que el modernista, "por americano y por hombre de su tiempo" (obsérvese la coincidencia con Blanco-Fombona) fuera un desartaigado, un intelectual cosmopolita. ${ }^{15}$ En 1959, Marinello ha vuelto a puntualizar su pensamiento sobre el cosmopolitismo modernista con ocasión de la excelente Breve bistoria del modernismo de don Max Henríquez Ureña. Distingue éste (n. 1885) en su libro dos etapas modernistas, una de "temas desentrañados de civilizaciones exóticas o de épocas pretéritas," es decir, una etapa esencialmente cosmopolita, y otra, posterior, en que los modernistas tendieron, sin abdicar a trabajar el lenguaje con arte, a "captar la vida y el ambiente de los pueblos de América, traducir sus inquietudes, sus ideales y sus esperanzas," 16 es decir, la etapa de Cantos de vida y esperanza, de Alma América, del Canto a la Argentina, de Odas seculares, etc. Pues bien, Marinello difiere de esta opinión, asentando la de que la "condición extranjeriza y absentista está en la entraña del modernismo, y tiene que ver con su razón de existencia," que es la de no dejar oít, con sus músicas enerventes, la angustia del hombre americano. ${ }^{17}$ Para él la llamada segunda etapa del modernismo no es sino la reacción contra el modernismo, que si se manifiesta en los mismos modernistas es porque ya han dejado de serlo. Insiste mucho Marinello en su reciente libro en poner frente a frente el activismo político de Martí y las reverencias ante monarcas, dictadores y potentados, de Darío. $\mathrm{La}$ "condición extranjeriza" que él considera esencial del modernismo poco debió tener que ver con ello porque podría argüírsele con palabras

14 Ibid., pp. 40-41.

15 Juan Marinello, "El modernismo, estado de cultura," en Literatura bis. panoamericana, Hombres, Meditaciones (México, 1937), pp. 119-123; ver especialmente la p. 120.

16 Max Hentiquez Ureña, Breve bistoria del modernismo (México, 1954), pp. 31 y 32 .

17 Juan Marinello, Sobre el modernismo; Polémica y definición (México, 1959), p. 21. 
de Enrique Anderson Imbert (n. 1910) que Martí "parece ya próximo a Darío por su mención a una cultura aristocrática, cosmopolita, esteticista," 18 y, con palabras de Bernardo Gicovate (n. 1922), que lo que Martí y Darío tienen de común, precisamente, es ser "sobre todo estudiosos abiertos a las diversidades de las culturas extranjeras sin estigmatizarlas como extranjeras," es decir, que lo que tienen de común es su cosmopolitismo intelectual, aunque en ese cosmopolitismo sea "Martí más dado al estudio del pensamiento trascendentalista norteamericano, Darío más inclinado al estudio de las innovaciones rítmicas y sensuales europeas." 19 Vemos, pues, que si en Blanco-Fombona el cosmopolitismo modernista era mirado con inquietud como un descastamiento, un inevitable desarraigamiento, causado por la "incertidumbre mental y racial" de América en aquella época, ese cosmopolitismo es visto por Marinello no sólo como un desarraigamiento, propio de su tiempo, sino como un fenómeno, americano sí, pero no al servicio de los pueblos de América. ${ }^{20}$ Este crítico se basa, claro está, en conceptos filosóficos de los que se deriva un concepto de la literatura y una manera de juzgarla con criterio principalmente social y político.

El ser "hombres de libros" referido a los modernistas es algo que viene siendo generalmente aceptado, aunque con distinto significado en la pluma de los varios críticos. Don Arturo Marasso Rocca (n. 1890) decía hace ya cuarenta años que los poetas de América han explorado la superficie de ajenas literaturas, han querido estar al corriente en la moda literaria $y$, si bien con ello han dado pruebas de espíritu amplio y noblemente curioso, a veces lo han hecho por mero dilettantismo, como remedo insípido.21 $\mathrm{Y}$ en 1955 repetía, pero con otro sentido, Bernardo Gicovate: "La sirena de la lectura rápida e indigesta nos ha cautivado desde hace mucho tiempo. Empero la tal enfermedad... es el signo también de una fuerza y una personalidad definida... es que, en cierto sentido, toda la poesía nuestra, quizá toda la poesía moderna, es poesía de cultura," y de una cultura cosmopolita de la que veía ejemplos precisamente, según antes se indicó, en Martí y en Dario, y en todos los modernistas, porque el modernismo - tras el desorden romántico- sig-

18 Anderson Imbert, Historia, I, 325.

19 Bernardo Gicovate, "El signo de la cultura en la poesía hispanoamericana," en La cultura y la literatura iberoamericanas (Memoria del Séptimo Congreso del Instituto Internacional de Literatura Iberoamericana, Berkeley, California, 1955). (Berkeley, Los Angeles y 'México, 1957), p. 121.

20 Marinello, Sobre el modernismo, p. 26.

21 Marasso Rocca, Estudios Literarios, p. 60. 
nifica eso para Gicovate: la vuelta a la tradición de cultura por medio del estudio de la tradición propia y, sobre todo, de las culturas extranjeras, abarcando lo extranjero como parte de lo americano. ${ }^{22}$ Así, el ser "hombres de libros," que era exceso de tinta y falta de tradición para Blanco-Fombona es visto ahora por Gicovate, uno de los críticos de la generación hispanoamericana que llega a la madurez, precisamente como algo propio y peculiar de su tradición.

Los extremos de aprobación y desaprobación del cosmopolitismo modernista que acabo de reseñar $-\mathrm{y}$ los ejemplos podrian multiplicarse- proceden mayormente de críticos hispanoamericanos. Veamos por un momento, como posible elemento de control, lo que dicen sobre el tema otros dos críticos, norteamericano el uno, español el otro.

Para Isaac Goldberg (1887-1938), en 1920, el cosmopolitismo de los modernistas hispanoamericanos era parte del cosmopolitismo general en todo el mundo de aquellos días; era el resultado de lo que él llamaba el "age-spirit," el espiritu de la época: "The age was growing cosmopolitan, this yearning for broader horizons that is myopically dismissed by some critics as mere novelty-seeking exoticism. Exoticism (in its prurient sense), there was; novelty-mongering there was, underneath, however, lay an age-spirit that vented itself in music, in art, in science, in economics." $23 \mathrm{El}$ cosmopolitismo modernista (del modernismo hispanoamericano y del de fuera de este continente) revela, para Goldberg, "the interpenetrating spirit of the age," 24 lo que levanta al cosmopolitismo a caracteres de universalidad. Hablando de Darío, por ejemplo, dice Goldberg que la sensibilidad del poeta lo hace universal, no un mero asimilador de modelos extranjeros, y que lo universal de su humanidad (el ser mallorquín a la vez que oriental, griego a la vez que español - iy cómo recuerda todo esto las palabras de Valera! - [ver mi primera cita de él en el texto y la de su carta a Menéndez y Pelayo en la nota 55]), y que lo universal de su humanidad, repito, le hace identificarse con todos los tiempos, todos los sentimientos, toda la naturaleza animada, todos los pueblos; en una palabra que para Goldberg Dario es, no solamente cosmopolita, sino cosmogónico.25

Por su parte, don Federico de Onís (n. 1885), en un sustancioso trabajo leído precisamente en la reunión de nuestra Asociación del año

\footnotetext{
22 Gicovate, "El signo de la cultura ...," pp. 117, 120, 121.

23 Isaac Goldberg, Studies in Spanisb-American Literature (New York, 1920), p. 15:

24 .Ibid., p. 74.

25 Ibíd., pp. 153 y 171.
} 
1949, nos rccordaba que la originalidad de los pueblos y de los individuos no se da en el aislamiento, sino en la comunicación con los demás, y que la época modernista es, con el Renacimiento, una de las dos épocas de máxima comunicación hispánica con el resto del mundo. Según ya lo había indicado en su Antología de 1934, ve Onís en el modernismo la forma hispánica de la crisis universal de las letras y del espíritu que inició la disolución del siglo XIX: "En la década de 18801890 surgen en Europa, como en América, individualidades aisladas que tienen como rasgo común la insatisfacción con el siglo XIX, cuando éste ha llegado a su triunfo, y ciertas tendencias entre las que descuellan el individualismo y el cosmopolitismo. Estas tendencias coincidían con rasgos propios de los hispanoamericanos," y por eso la extranjerización del modernismo fue, sobre todo, "expresión de su cosmopolitismo nativo, de su flexibilidad para absorber todo lo extraño sin dejar de ser el mismo"; de lo que resultó, en definitiva, "la busca y afirmación de lo propio a través de lo universal." Busca y afirmación que se activaron cuando en 1898 sale España definitivamente de América como poder político y aparece un decidido expansionismo de los Estados Unidos. Entonces resurge en la América española el "hispanismo" y aparece el temor a la norteamericanización, lo que encuentra sus voceros en modernistas tan significados como Darío y Rodó, ${ }^{26}$ iniciadores de una reorientación del propio modernismo.

Resumiendo: El cosmopolitismo de los modernistas, aceptado por críticos contemporáneos suyos, un Valera, un Rodó, un Sanín Cano o un Coester, causó luego desazón a un Blanco-Fombona, a los criollistas, a los autoctonistas, y explicado por un Goldberg, un Onís o un Max Hentiquez Ureña, es condenado hoy por un Marinello y reivindicado por un Gicovate, por citar los dos extremos. En cada caso se ha visto la doctrina que sustenta la respectiva crítica. La serie es clara en la Bolsa de la apreciación del modernismo: Valoración e inquietud, desvalorización y revalorización. Y el debate, como una espiral sin fin, continúa abierto.

Si tras la orgía de citas que precede - creo que inevitable dado el carácter de este trabajo- se me pidiera mi propia opinión sobre el

26 Federico de Onís, "Sobre la caracterización del modernismo" [1949], en España en América (Río Piedras, P. R., 1955), pp. 175-181, especialmente las $175,176,177$ y 180. 
tema del cosmopolitismo modernista, me limitaría a hacer una cita más, esta vez una auto-cita, y resumir así lo que hace pocos meses hube de escribir en otra oportunidad:27 Por los años de 1870 y 1880 Hispanoamérica iba enlazándose más y más con la vida de los grandes países industriales que extraían o compraban sus materias primas y que, a su vez, la proveían de productos manufacturados; la innigración europea en este continente adquiría grandes proporciones; los miembros de las clases dirigentes hispanoamericanas se sentían cada vez más hombres de negocios y sus puntos de vista tendían a ser los mismos que los de los financieros extranjeros con quienes trataban; hasta los clásicos caudillos acabaron por interesarse más en aprovechar su gobierno para apilar capitales que para recoger laureles o gozar del poder por el poder mismo. Es decir, Hispanoamérica pasaba de la era del nacionalismo romántico, conservador o liberal que fuera, a la del positivismo materialista. Porfirio Díaz y sus "científicos," la oligarquía de hacendados argentinos, - los salitreros chilenos pueden ejemplificar esta era. Muchos de los escritores hispanoamericanos de aquellos días, con Darío a la cabeza, no sentían simpatía por el materialismo prevalente en su tierra, de la misma manera y por las mismas razones que escritores europeos, de Baudelaire a Mallarmé, a Eugenio de Castro, a Gabriele d'Annunzio, a Oscar Wilde, no habían simpatizado o no simpatizaban con el que consideraban craso mundo de negocios europeo. En América, como en Europa, tales escritores sintieron la obligación de preservar la belleza y el idealismo frente a la fealdad de la vida diaria y el materialismo ambiente. Como para ellos la belleza era algo inmanente, sin necesaria relación con un país o un tiempo específicos, era de prever que abandonaran, como lo hicieron, el nacionalismo literario de sus inmediatos predecesores en la literatura. En otras palabras, puesto que no les gustaba el mundo real en torno fueron tan cosmopolitas en su mundo ideal como sus compatriotas materialistas lo eran en el del dinero. En Hispanoamérica esa situación duró desde los años de 1880 hastal los primeros días del siglo $\mathrm{xx}$ porque entonces, bajo el impacto de la guerra hispano-americana de 1898 y sus consecuencias territoriales y luego bajo el impacto del asunto de Panamá de 1903, hasta estos escritores tan poco nacionalistas, $\tan$ cosmopolitas, redescubrieron un especial sentimiento de hermandad hispánica y de solidaridad. Se sintieron temerosos del poder y del expansionismo de los

${ }_{27}$ Luis Monguió, "Nationalism and Social Discontent as Reflected in SpanishAmerican Literature," The Annals of the American Academy of Political and Social Science, vol. 334 [Latin America's Nationalistic Revolutions] (March, 1961), pp. 63-73, especialmente las 67-68. 
Estados Unidos nórdicos, protestantes, anglo-parlantes, y del peligro que constituían para la identidad de la Hispanoamérica indo-latina, católica, hispanohablante. $Y$ sintieron entonces la obligación de teafirmar los valores espirituales constituidos por su lengua, su nacionalidad, su religión, su tradición. Para ellos, estos valores daban a Hispanoamérica su significado, ciertamente un significado más alto a sus ojos que los valores materiales de sus propios compatriotas que miraban a lo positivo y que por ello, frente al superior poder de los Estados Unidos, cuyo utilitarismo compartían, no podían constituir un baluarte de hispanoamericanismo. Rodó con su Ariel (1900), Darío con sus Cantos de vida y esperanza (1905), Lugones con sus Odas seculares (1910), por ejemplo, trataron de alzarlo. Estos modernistas, tan cosmopolitas por amor al ideal, supieron volver los ojos a su América, por razón del mismo amor, para exaltar los bellos valores que creían esenciales a la integridad de su tradición y de su tierra. En lenguas múltiples, aprendidas en su mundo cultural cosmopolita, por su raza habló su espíritu.

University of California

LuIs MoNGuió

Berkeley 4, California 